\title{
Genetic testing in Italy, year 2004
}

\author{
Bruno Dallapiccola ${ }^{\star 1,2,3}$, Isabella Torrente ${ }^{1,2}$, Arnaldo Morena ${ }^{1,2}$, Franca Dagna-Bricarelli ${ }^{4}$ \\ and Rita Mingarelli ${ }^{1,2}$
}

\begin{abstract}
${ }^{1}$ Istituto CSS-Mendel, Viale Regina Margherita, Rome, Italy; ${ }^{2}$ Casa Sollievo della Sofferenza Hospital, IRCCS, San Giovanni Rotondo, Italy; ${ }^{3}$ Department of Public Health and Pathology, La Sapienza University, Genoa, Italy; ${ }^{4}$ AO Galliera, Department of Human Genetics, Genoa, Italy
\end{abstract}

A comprehensive and long-range monitoring of genetic testing is ongoing in Italy starting from 1987. The data collected by the last survey of year 2004, on behalf of the Italian Society of Human Genetics, included the activities of 88 clinical centres and 160 cytogenetic and 183 molecular genetic laboratories, hosted by 256 structures. Only $42 \%$ of them fulfilled the requirements of current Italian legislation. Genetic tests included 283601 cytogenetic analyses. There have been 120238 invasive prenatal samplings, 84\% of which were amniocenteses. A significant north-to-south decreasing gradient was evident for all activities. This study has also surveyed 190610 molecular genetic tests. CFTR gene analysis accounted for $23 \%$ of prenatal and $29 \%$ of postnatal molecular tests. In total, 420 different genes have been investigated, 10 of which comprised three-quarters of the whole activity. More than $10 \%$ of molecular tests were performed on fetal samples, the analysis of CFTR, DMD, FMR1, FMR2, and GJB2 genes accounting for $83 \%$ of all prenatal tests. In years 1997-2004, the demand of cytogenetic tests has increased two-fold and that of molecular tests has increased four-fold. Only $16 \%$ of cytogenetic and $12.5 \%$ of molecular tests have been followed by genetic counselling. This survey highlights the need for a major basic intervention in the general organisation of genetic structures in Italy, which should be rationalised in accordance with the national guidelines, and the necessity of constant training of general practitioners and education of consumers to the appropriate use of genetic testing.

European Journal of Human Genetics (2006) 14, 911-916. doi:10.1038/sj.ejhg.5201653; published online 24 May 2006

Keywords: genetic testing; cytogenetics; molecular genetics; genetic survey; prenatal testing; genetic counselling

\section{Introduction}

Genetic testing is the major translational product of genetic research into practical medicine. The request for genetic tests has dramatically increased over the past 20 years, in parallel with the expanded knowledge on the biological mechanisms underlying human diseases. At present, in addition to chromosome anomalies, more than 1500 genetic disorders can be tested at the molecular level. Thus, the use of such tests reflects the advances of genetic research and the

*Correspondence: Professor B Dallapiccola, Istituto CSS-Mendel, Viale Regina Margherita, 261, 00196 Roma, Italy. Tel: + 3906 44160573; Fax: + 3906 44160548; E-mail: dallapiccola@css-mendel.it Received 8 December 2005; revised 13 April 2006; accepted 19 April 2006; published online 24 May 2006 changes in medicine and in the human health market. To manage this impressive transformation, some countries, including Italy, have developed guidelines regulating the activities of clinical and laboratory genetic services. In particular, an agreement between the Ministry of Health and the 20 Italian Regions has been established on 15 July 2004 , to set roles and functions of genetic departments and laboratories, with major emphasis on the autonomy of these structures within the National Health System. ${ }^{1}$

The Italian Societies of Human Cytogenetics (AICM) and Medical Genetics (AIGM), which merged into the Italian Society of Human Genetics (SIGU) in 1998, started monitoring genetic testing in Italy in 1987. The first four surveys (years 1987, 1989, 1991, 1994) ${ }^{2-5}$ collected information 
concerning only cytogenetic tests, whereas surveys of years 1995-1996, 1997, 2000, 2002, ${ }^{6-11}$ and 2004 gathered data on both cytogenetic and molecular tests. The last four surveys were carried out by rather homogeneous criteria, thus obtaining specific information on the transformation occurring in Italy from 1997 onwards, with respect to genetic testing availability, organisation, and utilisation.

This report summarises the genetic activities performed in Italy during the year 2004 and provides an overview of the changes that occurred over a 7-year period. Data were collected on a nationwide basis by the CSS-Mendel Institute in Rome, on behalf of the SIGU.

These results provide useful information to ponder on the availability and the use of these medical resources and to encourage a critical evaluation, which will benefit future genetic services planning and, in a more general perspective, genetic testing activities.

\section{Methods}

Data surveyed in 2004 were collected from the Italian genetic structures notified by universities, general and research hospitals, and private laboratories and listed in the SIGU database. Moreover, additional genetic testing services were identified through an Internet search and validated by qualified experts. Genetic structures were not required to fulfil any quality standard in order to take part in the survey.

Data were loaded online by each participating centre, which accessed the SIGU website through a private username and password assigned during the registration process. Each laboratory was asked to complete five forms, including personal data, cytogenetic, molecular genetic, immunogenetic, and clinical forms. Data collected included number and type of processed analyses, reason for referral, related clinical activities, and number of personnel employed.

Although the participation to this survey was voluntary, we estimate that the obtained data covered at least 95\% of the national genetic testing activity, based on the high response rate, and all centres included in previous surveys also participated in the 2004 survey. Collected data were not subjected to verification; however, it is worth to note that two regions (Lombardia and Emilia Romagna), which independently performed similar surveys, gathered information comparable to our study.

The four past consecutive surveys (from 1997 to 2004) were performed adopting standardised criteria, thus allowing an accurate evaluation of the changes that occurred in the genetic testing services in Italy.

\section{Results}

The living Italian population in 2004 accounted for over 58 million individuals and the newborn population 562000 .
The survey of year 2004 has monitored the activity of 88 clinical centres and 160 cytogenetic and 183 molecular genetic laboratories (including 10 immunogenetic laboratories), hosted by 256 structures. Only $42 \%$ of them fulfilled the requirements of the current Italian legislation, which commits genetic testing to specialised medical genetic laboratories. Therefore, 58\% of genetic testing was performed by other service providers, including clinical chemistry, immunology, haematology, histopathology, and oncology departments. In addition, only $41 \%$ of the structures were certified according to the ISO 9000-9002 certification. Thirty per cent of the genetic structures were affiliated to universities, $27 \%$ belonged to general hospitals, $12 \%$ to research hospitals, $11 \%$ to local health services, $16 \%$ were private organisations, whereas $4 \%$ had a different affiliation. Concerning the territorial distribution of the genetic structures, there was a consistent north-to-south decreasing gradient, with about half of them being located in the eight northern regions and the remaining structures in the 12 central, southern, and islander regions (Table 1). This unbalanced distribution is supported by the lower figures of the average population served by each centre in northern Italy, compared to other regions.

There were 2372 genetic employees, of whom $56 \%$ were graduates (36\% biologists, 16\% medical doctors, and 6\% with other degrees). Temporary employees made up $27 \%$ of personnel.

The total number of genetic tests performed in the year 2004 is summarised in Table 2.

Figure 1 provides a review of the different cytogenetic analyses. Out of 283601 cytogenetic tests, 51.7\% were prenatal. There had been 120238 invasive prenatal samplings, of which $84 \%$ were amniocenteses, $15 \%$ chorionic villi sampling (CVS), and about $1 \%$ fetal blood samplings. Regarding postnatal chromosome analyses, $82 \%$ dealt with constitutional cytogenetic and $18 \%$ with cancer cytogenetic studies. More than 47000 molecular cytogenetic tests had been performed, including $42 \%$ prenatal analyses. Overall, 93\% were represented by FISH and 7\% by subtelomeric rearrangement analyses.

About 34 and $31 \%$ of constitutional and cancer cytogenetic analyses were carried out in a single northen region (Lombardia). Likewise, $28 \%$ of cytogenetic analyses on amniocytes were performed in Lombardia, followed by Lazio (15\%, central region), Emilia-Romagna (9\%, northern region), and Sicily (9\%, islander region). Up to $70 \%$ of CVS were performed in two northern regions (Lombardia, 48\%; Emilia-Romagna, 22\%). Similarly, 25\% of fetal blood samples were collected in Emilia-Romagna and 23\% in Lombardia. These figures are likely related to the specific technical skills of some obstetricians operating in these regions.

The survey of year 2004 has scrutinised 190610 molecular genetic tests, of which $10.7 \%$ were prenatal 
Table 1 Territorial distribution of medical genetic centres, living population, and average size of the population served by each centre in Italy

\begin{tabular}{|c|c|c|c|c|}
\hline Area & Region & Living population & Medical genetic centres & Population/no. centres ratio \\
\hline Northern & $\begin{array}{l}\text { Emilia Romagna } \\
\text { Friuli Venezia Giulia } \\
\text { Liguria } \\
\text { Lombardia } \\
\text { Piemonte } \\
\text { Trentino Alto Adige } \\
\text { Valle D'Aosta } \\
\text { Veneto }\end{array}$ & $\begin{array}{r}4151369 \\
1204718 \\
1592309 \\
9393092 \\
4330172 \\
974613 \\
122868 \\
4699950\end{array}$ & $\begin{array}{r}20 \\
7 \\
11 \\
42 \\
14 \\
3 \\
1 \\
27\end{array}$ & $\begin{array}{l}207.568 \\
172.103 \\
144.755 \\
223.645 \\
309.298 \\
324.871 \\
122.868 \\
174.072\end{array}$ \\
\hline Total & & 26469091 & 125 & 211.753 \\
\hline Central & $\begin{array}{l}\text { Lazio } \\
\text { Marche } \\
\text { Toscana } \\
\text { Umbria }\end{array}$ & $\begin{array}{r}5269972 \\
1518780 \\
3598269 \\
858938\end{array}$ & $\begin{array}{r}27 \\
3 \\
16 \\
5\end{array}$ & $\begin{array}{l}195.184 \\
506.260 \\
224.892 \\
171.788\end{array}$ \\
\hline Total & & 11245959 & 51 & 220.509 \\
\hline Southern & $\begin{array}{l}\text { Abruzzo } \\
\text { Basilicata } \\
\text { Calabria } \\
\text { Campania } \\
\text { Molise } \\
\text { Puglia }\end{array}$ & $\begin{array}{r}1299272 \\
596546 \\
2009268 \\
5788986 \\
321953 \\
4068167\end{array}$ & $\begin{array}{r}3 \\
3 \\
5 \\
22 \\
2 \\
18\end{array}$ & $\begin{array}{l}433.091 \\
198.849 \\
401.854 \\
263.136 \\
160.977 \\
226.009\end{array}$ \\
\hline Total & & 14084192 & 53 & 265.739 \\
\hline Islander & $\begin{array}{l}\text { Sardegna } \\
\text { Sicilia }\end{array}$ & $\begin{array}{l}1650052 \\
5013081\end{array}$ & $\begin{array}{r}6 \\
21\end{array}$ & $\begin{array}{l}275.009 \\
238.718\end{array}$ \\
\hline Total & & 6663133 & 27 & 246.783 \\
\hline Total Italy & & 58462375 & 256 & 228.369 \\
\hline
\end{tabular}

Table 2 Genetic testing in Italy in the year 2004

\begin{tabular}{lccc}
\hline & $\begin{array}{c}\text { Cytogenetic } \\
\text { tests }\end{array}$ & $\begin{array}{c}\text { Molecular } \\
\text { genetic tests }\end{array}$ & Total \\
\hline Postnatal & 136845 & 170268 & 307113 \\
Prenatal & 146756 & 20342 & 167098 \\
Total & 283601 & 190610 & 474211 \\
\hline
\end{tabular}

diagnoses. About $53 \%$ of them were performed in northern regions, $23 \%$ in central regions, $12 \%$ each in southern and islander regions. Whereas the distribution of postnatal molecular tests confirmed a north-to-south decreasing gradient, prenatal tests were mostly located in a unique central region (Lazio, 71\%). This result reflects the commercial promotion of a few private laboratories, advertising the analysis of CFTR, DMD, FMR1, FMR2, and GJB2 genes on amniocytes and trophoblast cells in the absence of any specific parental risk. In fact, the analysis of these genes accounted for $83 \%$ of all prenatal molecular diagnoses. The list of the top 10 analysed genes, covering more than $97 \%$ of all prenatal molecular tests, is shown in Table 2. Table 3 summarises the 10 most requested postnatal molecular analyses, which represent about $70 \%$ of all tests. CFTR gene analysis accounted for $23 \%$ and was mostly connected with infertility screening, whereas the analysis of three genes involved in trombophilia (factor $\mathrm{V}$ Leiden, FGA, and MTHFR) accounted for 25\%, and HLA for $9 \%$ of all tests. The major indication to HLA testing was disease-association studies. In total, 420 different genes have been investigated.

Interestingly, private laboratories performed $6.5 \%$ of postnatal cytogenetic tests and $5.5 \%$ of postnatal molecular tests (Table 4). These numbers well correspond to the territorial prevalence of such private structures. Conversely, the figures related to prenatal tests were consistently different, with $23 \%$ cytogenetic and $56.6 \%$ molecular genetic tests carried out by private organisations.

Figure 2 summarises the increase in the demand for cytogenetic and molecular genetic tests over the years 1997-2004 in Italy. 


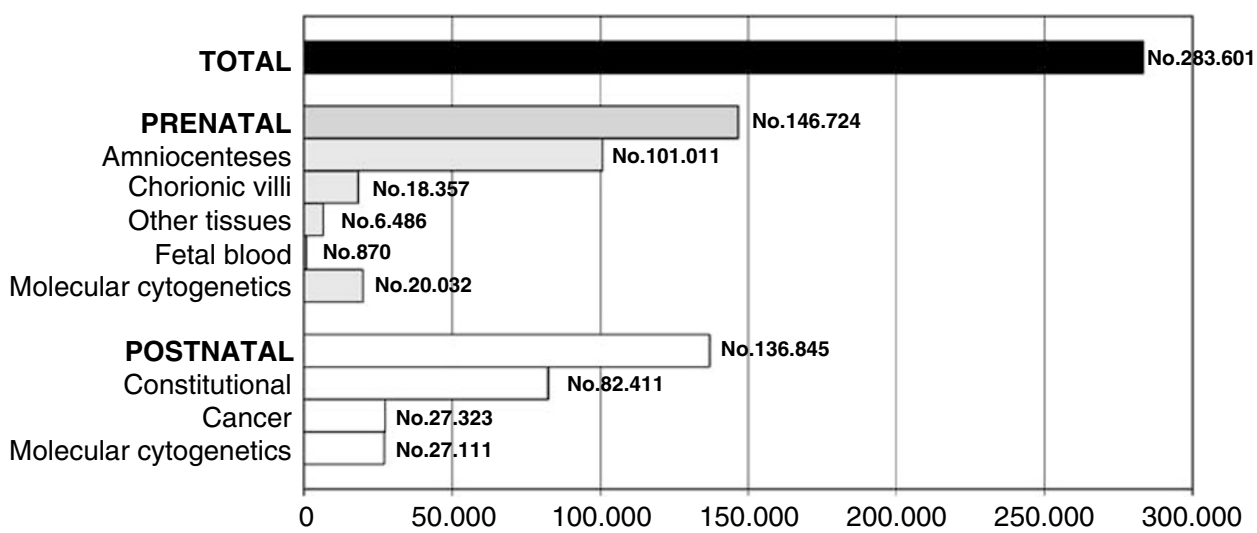

Figure 1 Cytogenetic tests in Italy in year 2004.

Table 3 Top 10 prenatal molecular genetic tests in Italy, year 2004

\begin{tabular}{lccr}
\hline Disease/gene & No. of tests & No. of centres & No. of regions \\
\hline Cystic fibrosis (CFTR) & 5956 & 27 & 12 \\
Duchenne muscular dystrophy (DMD) & 3767 & 10 & 9 \\
Genetic deafness (GJB2) & 3659 & 16 & 6 \\
Mental retardation (FMR1) & 2417 & 1 & 11 \\
Aneuploidy chromosomes 13,18,21,X,Y & 1488 & 1 & 1 \\
Mental retardation (FMR2) & 1010 & 15 & 1 \\
$\beta$-Thalassemia (HBB) & 830 & 12 & 7 \\
Uniparental disomy & 386 & 11 & 8 \\
Achondroplasia/Hypochondroplasia (FGFR3) & 220 & 11 & 8 \\
Spinal muscular athrophy (SMN1) & 75 & & 7 \\
\hline
\end{tabular}

Table 4 Top 10 postnatal molecular genetic tests in Italy, year 2004

\begin{tabular}{|c|c|c|c|}
\hline Disease/gene & No. of tests & No. of centres & No. of regions \\
\hline Cystic Fibrosis (CFTR) & 38971 & 82 & 17 \\
\hline HLA & 17099 & 8 & 7 \\
\hline Coagulation factor V(Factor V Leiden) & 15366 & 46 & 14 \\
\hline Coagulation Factor II (F2) & 13968 & 43 & 14 \\
\hline Methylenetethrahydrofolate reductase(MTHFR) & 13667 & 47 & 14 \\
\hline Leukemia (different genes) & 6093 & 10 & 8 \\
\hline Mental retardation (FMR1) & 5166 & 47 & 14 \\
\hline Azoospermia Yq loci & 4723 & 70 & 16 \\
\hline Haemochromatosis (HFE) & 4302 & 45 & 15 \\
\hline Genetic deafness (GjB2) & 3125 & 40 & 14 \\
\hline
\end{tabular}

Finally, the clinical genetic structures performed 52599 genetic consultations, including dysmorphisms (19\%), Mendelian disorders (15\%), prenatal chromosome anomalies (13\%), and mental retardation (10\%).

In agreement with the Italian legislation, it is expected that genetic testing should be accompanied by information and followed by genetic counselling, when indicated. However, only $16 \%$ of the total genetic tests and $12.5 \%$ of molecular tests have been followed by genetic counsel- ling. This means that a large proportion of genetic testing in Italy is performed without proper information, mostly because of the lack of specialisation in human genetics of many services.

\section{Discussion}

The number of genetic structures providing clinical and laboratory services in Italy is impressive and, as far as we 

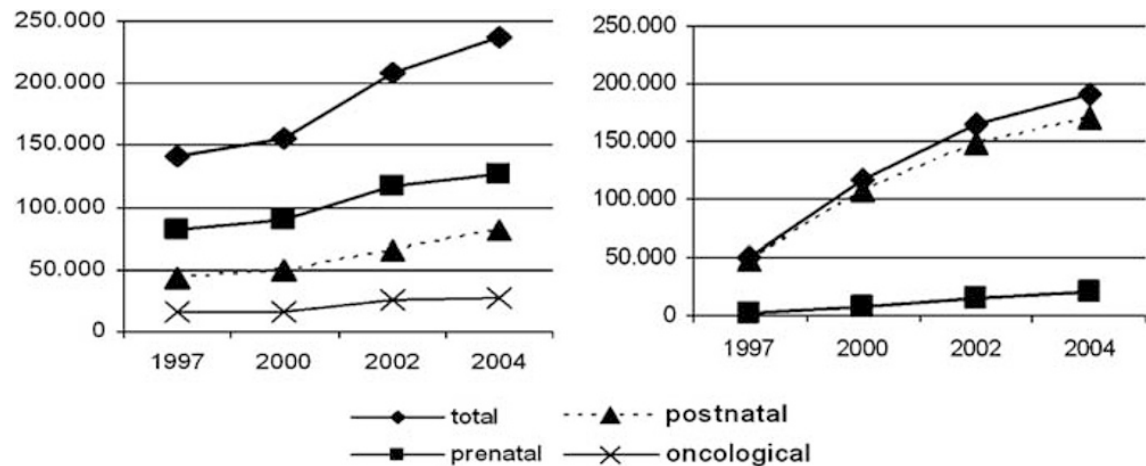

Figure 2 Prenatal and postnatal cytogenetic (left) and molecular genetic tests in Italy in years 1997-2004.

know, it has no equivalent in Europe. This anomaly reflects the historical absence of programmes related to the genetic activities in Italy, which has resulted both in an excessive number of diagnostic laboratories and a non-homogeneous territorial distribution. Nevertheless, it is difficult to understand why the number of genetic laboratories has continued to expand also in recent years (233 in 1997, 431 in 2004) despite the SIGU recommendation, which have urged health-care providers to review the network of structures and to reduce their number, in order to improve the quality, cut the costs, and expand the list of available services. It is likely that the lack of any interregional coordination has been a major drawback to delivering of this quite obvious action.

The number of cytogenetic tests has doubled from 1997 (141046 analyses) to 2004 (283 601 analyses). Invasive prenatal tests have increased up to about 120000 , with a minor increase during the last 2 years, which suggests that this activity has probably reached a plateau, with about one in five newborns having had the pregnancy monitored. In this regard, the absolute number of prenatal tests would appear adequate to the current figure of $20-25 \%$ pregnant women aged 35 or more. However, about 23\% of Italian women receiving prenatal tests are less than 35-year-old, meaning that, for some reason, a comparable number of aged mothers did not monitor their pregnancies using an invasive technique.

The number of molecular genetic tests has increased about four-fold since 1997 (50367, versus 190610 in 2004). However, the total number of investigated genes remains rather low (420, compared to 290 in 2002), and threequarters of all analyses refer to only 10 genes. Based on these data, the network of molecular diagnostic structures in Italy should be seriously reconsidered.

One of the most impressive results in the present survey refers to the astonishing number of prenatal molecular tests, which accounts for more than $10 \%$ of all molecular analyses. As anticipated, this figure reflects a commercial activity fostered by the private health market. There is no doubt that the direct search of some common mutations, like CFTR and GJB2, in amniocytes and trophoblast cells rather than in the parental blood is in disagreement with the good clinical genetic practice, and has some negative sequels in the parents of those $2-3 \%$ fetuses in which one of these common mutations is found.

To our knowledge, no other European country has settled a comprehensive and long-range monitoring of genetic testing at the national level, as Italy. However, there are several surveys that have provided snapshots on the state of these activities. Harris and $\operatorname{Reid}^{12}$ have compared availability, access, and uptake of genetic testing across 31 European countries. Over 20000 genetic tests had been carried out in the year 2000 in the Netherlands for about 250 different genetic disorders. ${ }^{13}$ In the same year, the UK Clinical Molecular Genetic Society estimated that over 50000 tests were carried out in that country. ${ }^{14} \mathrm{~A}$ similar figure (45000 tests) was reported in Spain in 2001, referring to the activity of 53 centres providing the analysis of 241 genetic conditions. ${ }^{15}$ The European Directory of DNA Diagnostic Laboratories (EDDNAL) has listed 313 laboratories and 580 genetic conditions for which tests were available in the year 2003. ${ }^{16}$ An EMQN European survey conducted in 2002 and involving only public centres estimated 381000 genetic tests performed in 352 specialist clinical molecular genetic laboratories. ${ }^{17}$ A subsequent survey of genetic testing in Europe estimated that more than 700000 analyses had been performed in 2002, with a greater than $100 \%$ increase per year in some member states. At that time, there were 751 genetic testing laboratories and 936 additional clinical chemistry/haematology centres documenting similar activities. ${ }^{17}$ A more recent comprehensive survey has measured the amount of genetic services in Germany between 1996 and 2002, by making use of the central database of the national healthcare system, and by inquiring with private health insurances. A three-fold increase of DNA-based testing was documented (from about 60000 to 175000 ), whereas cytogenetic analyses and genetic counselling had remained 
constant. $^{18}$ In general, most of these data indicate a substantial increase of genetic testing activities in the EU, along with an imbalance in the distribution of centres, reflecting the unplanned development of genetic testing in many countries. They also show that a large part of the activity is focused on diagnostic testing for a limited number of diseases, the most frequently performed tests correlating with traits and disorders with high incidence in the general population.

In conclusion, the Italian genetic testing survey addresses two major issues. Firstly, the need for some basic intervention in the general organisation of the genetic structures, which should be rationalised in accordance with the national guidelines, with the goals of providing tests of the highest quality, to link testing and genetic counselling, to cut the costs, and to widen the number of available services. These changes should be planned also in the perspective of an average 10-30\% increase per year of the genetic testing demand, according to national and international expectancies. ${ }^{18,19}$ Secondly, the need for constant training of the general practitioner and education of the consumer with regard to appropriate use of genetic tests, which should flank and sustain the good clinical practice. In this respect, a more sparing use of genetic tests, which should always follow specific clinical indications, must be recommended.

It is likely that the genetic testing surveys carried out in Italy during the last 20 years on behalf of the SIGU have now reached the end of the line. In fact, the EuroGentest programme, a European network of excellence aimed at harmonising genetic testing services, ${ }^{20}$ in collaboration with Orphanet, ${ }^{21}$ a free access European portal providing information on services dedicated to rare diseases and orphan drugs, is launching in 2006 the collection of cytogenetic, biochemical, and molecular genetic testing in the EU. The set of information and the experience gathered by the Italian census and similar surveys will possibly serve as a model to start this new comprehensive European laboratory database, and contribute to speed up the process of standardising the infrastructures, tools, resources, guidelines, and procedures, which are expected to raise, adjust, and improve the quality of genetic testing in our Continent.

\section{Acknowledgements}

This study was supported in part by the Italian Ministry of Health Ricerca Corrente 2006, and by contract no. 512148 (LSHB-CT-2004512148) Network of Excellence - EuroGenTest.

\section{References}

1 Conferenza Stato-Regioni. Atto n. 2045 - Seduta 15 luglio 2004.: Linee-guida per le attività di genetica medica. Gazzetta Ufficiale, no. 224, September 23, 2004.

2 Forabosco A, Dagna Bricarelli F: Laboratori di Diagnostica Citogenetica, $\mathrm{I}^{\circ}$ indagine nazionale. Analysis 1987; 10: 21-29.

3 Piombo G: Laboratori di Citogenetica, II $^{\circ}$ indagine nazionale anno 1989. Analysis 1990; 10: 5-20.

4 Piombo G, Mantero M: Censimento dei Laboratori di Citogenetica - anno 1991, III $^{\circ}$ indagine nazionale. Analysis 1993; 2: $41-57$.

5 Dagna Bricarelli F, Dallapiccola B, Mantero M, Mingarelli R, Gavaciuto D, Martelli A: Malattie genetiche: guida dei servizi e delle associazioni. Ministero della Sanità, Italsiel, Roma 1994; 1: 8-145.

6 Dallapiccola B, Mingarelli R, Miotti S, Novelli G: Indagine sulla diagnosi molecolare in Italia: anni 1995-1996. Rapporti ISTISAN 1998; 20: 29-36.

7 Santucci S, Ranzi A, D'Ippolito C, Spagnolo A, Forabosco A: Indagine sulla diagnosi citogenetica prenatale in Italia: anni 1995-1996. Rapporti ISTISAN 1998; 20: 37-57.

8 Dallapiccola B, Torrente I, Mingarelli R, Novelli G: Censimento della diagnosi genetica in Italia - 1997. Tendenze Nuove 2000; 16 (Suppl 3): 5-90.

9 Dallapiccola B, Torrente I, Mari A, Mingarelli R: Censimento dei test genetici in Italia - Anno 2000. Analysis 2002; 5/6: 292-360.

10 Dallapiccola B, Torrente I, Morena A, Mingarelli R, Dagna Bricarelli F: Censimento delle strutture di genetica medica e dei test genetici in Italia - anno 2002. Anaysis 2004; 2/3: $301-403$.

11 Società Italiana di Genetica Umana. . URL: http://www.sigu.net.

12 Harris R, Reid M: Medical genetic eervices in 31 countries: an overview. Eur J Hum Genet 1997; 5 (Suppl 2): 3-21.

13 Health Council of the Netherlands: DNA Diagnostics publication num. 1998/11E Bezoekadres Parnassusplein 5, 2511 VX. DenHaag, Netherlands 1998.

14 Patton S, Barton D, Elles R: Retaining the confidence of the public in molecular genetic testing - quality assurance. Commun Genet 2000; 3: 164-169.

15 Rueda J, Briones E: Genetic testing services for hereditary diseases in spain: results from a survey; in: Ibarreta D, Bock AK, RodriguezCerezo E (eds): Report EUR 20516EN, European Commission, Joint Research Center 2002.

16 European Directory of DNA Diagnostic Laboratories (EDDNAL), http://www.eddnal.com.

17 Ibarreta D, Elles R, Cassiman JJ, Rodriquez-Cerezo E, Dequeker E: Towards quality assurance and harmonization of genetic testing services in the European Union. Nature Biotechnol 2004; 22: $1230-1235$.

18 Schmidtke J, Pabst B, Nippert I: DNA-based genetic testing is rising steeply in a national health care system with open access to services: a survey of genetic test use in Germany, 1996-2002. Genet Test 2005; 9: 80-84.

19 McGovern MM, Benach MO, Wallestein S, Desnick FJ, Keenlyside $\mathrm{R}$ : Quality assurance in molecular genetic testing laboratories. J Am Med Assn 1999; 281: 835-840.

20 Cassiman JJ: EuroGentest - a European network of excellence aimed at harmonizing genetic testing services. Eur J Hum Genet 2005; 13: 1103-1105.

21 Orphanet - Rare diseases - Orphan drugs. URL: http://www. orpha.net. 